\title{
Development of Fe-Cr-Ni-Mn-N High-Alloyed Powder Processed by Mechanical Alloying
}

\author{
Anatoly A. Popovich, Nikolay G. Razumov, Alexey O. Silin, Evgeniy L. Gulihandanov \\ Saint-Petersburg State Polytechnical University, Saint-Petersburg, Russia \\ Email: n.razumov@onti.spbstu.ru
}

Received June 26, 2013; revised July 26, 2013; accepted August 4, 2013

Copyright (C) 2013 Anatoly A. Popovic et al. This is an open access article distributed under the Creative Commons Attribution License, which permits unrestricted use, distribution, and reproduction in any medium, provided the original work is properly cited.

\begin{abstract}
The present work shows the research results of phase formation in obtaining high-alloy powder of Fe-Cr-Ni-Mn-N by mechanochemical synthesis in various gas atmospheres.
\end{abstract}

Keywords: Ferrous; Nitrogen; Ammonia; Mechanical Alloying; Austenite; High Nitrogen Steel

\section{Introduction}

The most important tasks of modern materials science are the development of new materials capable working in extreme conditions, and the development of effective technologies for their preparation. Such materials represent significant interest in austenitic stainless steels, which are known for their unique complex of mechanical, physical and chemical properties [1].

Currently, there is a clearly strong trend towards increasing the use of nitrogen as an alloying element in a corrosion-resistant iron-based alloy. Nitrogen as an alloying element in such alloys is superior than other elements for austenite forming and hardening ability. Nitrogen use in these alloys solves the problem of increasing the strength and cost savings of expensive and scarce alloying elements such as nickel, cobalt and manganese. In addition, it is possible to create alloys with the best quality and combination of mechanical and technological properties in comparison with typical conventional steels.

Austenitic steel with high nitrogen content produces by different ways, such as: melting and solidification in a nitrogen atmosphere, high-temperature solid phase sintering and others. But for a high nitrogen, content in the metal is necessary to increase pressure of nitrogen atmosphere, and combination with a high temperature makes the process dangerous.

Furthermore, because of the high temperatures required for steel melting, almost invariably obtained materials with a coarse grain structure, which have poor mechanical properties. Since austenitic steel grain size cannot be reduced by thermal treatment, it requires multiple pressure processing which eventually leads to the increasing of the technology cycle duration, the energy consumption and the material cost.

In this regard, reduction of the high-nitrogen austenitic steels grain size has been studied intensively. Great importance in this task belongs to mechanical alloying technology.

According to some authors [2,3], mechanochemical methods of materials treatment are comparable by its power density to the electron-beam treatment, and by the effects on phase transformations to the shock-wave treatment [4]. A distinctive feature of mechanochemical processes is a high dose of energy delivered to the material at a time. Recently, mechanical alloying method is used to produce "super equilibrium" concentrations of nitrogen in iron-based alloys [3,5-7]. In this case, nitration occurs during mechanical activation of the starting components in an ammonia atmosphere. The nitrogen content in iron powder can reach $0.6 \%-0.7 \%$, and in the composition of $\mathrm{Fe}^{+} 25 \%$ and $\mathrm{Ti} 1.5 \%$ [2,8]. Nitrogen is a strong austenite (stabilizer) element, so the study of its effect on the phase composition of mechanical alloyed steel is very interesting.

\section{Experimental Procedure}

The aim of this work is to study the phase formation and the influence of the mechanical activation atmosphere on the iron mechanical alloying process by austenite elements in the system Fe-Cr-Ni-Mn-N.

Mechanical alloying of the investigated powders was carried out in hermetic reactor of high-energy strain vibration mill in ammonia or nitrogen atmosphere by the method described in $[2,3]$. The process scheme of me- 
chanical alloying used in SPbSPU is shown in Figure 1. Powders of iron, chrome, electrolytic nickel and manganese with a powder size less than 200 microns were used as initial components. The weight ratio of feed powder to the ball mass is from 1:10 to 1:25. Grinding time is from 1 to 5 hours. Particle size distribution of the alloy was determined using a laser particle analyzer Fritsch ANALYSETTE 22. Phase composition of the samples was investigated by X-ray analysis on a diffractometer Bruker D8 ADVANCE (Germany) in CuK $\alpha$-rays $(\mathrm{U}=40 \mathrm{kV}$, I $=40 \mathrm{~mA}$ ). Processing of the diffractometer data was performed by EVA and Topaz programs. The elements distribution in the volume of the powder particles was studied by X-ray wave dispersional microanalysis on polished samples using a scanning electron microscope MIRA 3 LMH with attachment Oxford INCA Wave 500. Locality of the chemical composition determination is 1 $1.5 \mu \mathrm{m}$, the absolute error of this method is $\pm 0.1 \%$. The nitrogen content of the alloy was determined by LECO TC400. Fine structure of the alloys was studied using transmission electron microscopy Technai S-Twin G230 and XRD (BRUKER D8 ADVANCE, $\mathrm{CuK} \alpha$ ).

\section{Results and Discussion}

Figure 2 shows the size distribution of the alloy obtained in different atmospheres. The graph shows that the mechanical alloying atmosphere does not significantly affect the size of the resulting powder.

Figure 3 shows the phase composition change of the Fe-18Cr-8Ni-12Mn-N alloy as a function of mechanical activation time and atmosphere time. From the figure we can see that with increasing mechanical activation time, regardless of the atmosphere, the amount of $\gamma$-phase increases. In this case after 3.5 hours of mechanical activation $\gamma$-phase share in the alloy reaches $90 \%$-for ammonia atmosphere and $70 \%$ for nitrogen atmosphere. It should also be noted that the increase austenite content in the alloy in the initial stages of mechanical activation in a nitrogen atmosphere is more intensive.

Figure 4 shows the elements distribution in the volume of powder particles for the $\mathrm{Fe}-18 \mathrm{Cr}-8 \mathrm{Ni}-12 \mathrm{Mn}-\mathrm{N}$ alloy depending on the time of mechanical activation. As can be seen the increase of the mechanical activation time results in a more uniform distribution of alloying elements in powder particles volume.

Figure 5 shows the variation of nitrogen content in the Fe-18Cr-8Ni-12Mn-N alloy depending on the time of mechanical activation and atmosphere. With increasing the time of mechanical activation, nitrogen content in the alloy increases. After 3.5 hours of treatment in an atmosphere of ammonia nitrogen content is $0.922 \%$, while under treatment in a nitrogen atmosphere- $0.04 \%$. This implies that the nitrogen saturation of the alloy in an ammonia atmosphere is faster. This is due to the fact that during the grinding process ammonia dissociates and saturation takes place in an atmosphere of atomic nitrogen. The saturation of the alloy with nitrogen by grinding in molecular nitrogen atmosphere is different and discussed more detail in [3]. To achieve the nitrogen content in the alloy about $0.9 \%$ by grinding in nitrogen, mechanical activation process should last for more than 20 hours. It should be noted that an increase in nitrogen content increases the proportion of austenite, which proves the fact that nitrogen is a strong $\gamma$-phase stabilizer.

Fine crystalline structure was studied by high-resolution transmission electron microscopy in order to obtain more detailed information about the structure and size of the nanocrystals in the alloy. Figures 6(a) and (b) show a typical nanocrystalline structure of mechanical alloyed high-nitrogen powder alloy of Fe-18Cr-8Ni-12Mn- $0.9 \mathrm{~N}$ system. These images show that the size of the nanocrystals is in the range from 6 to $20 \mathrm{~nm}$. According to X-ray analysis of the alloy obtained by Bruker D8 ADVANCE, the nanocrystals size is in the range from 18 to $36 \mathrm{~nm}$ (Table 1). Image analysis showed that the nanocrystals

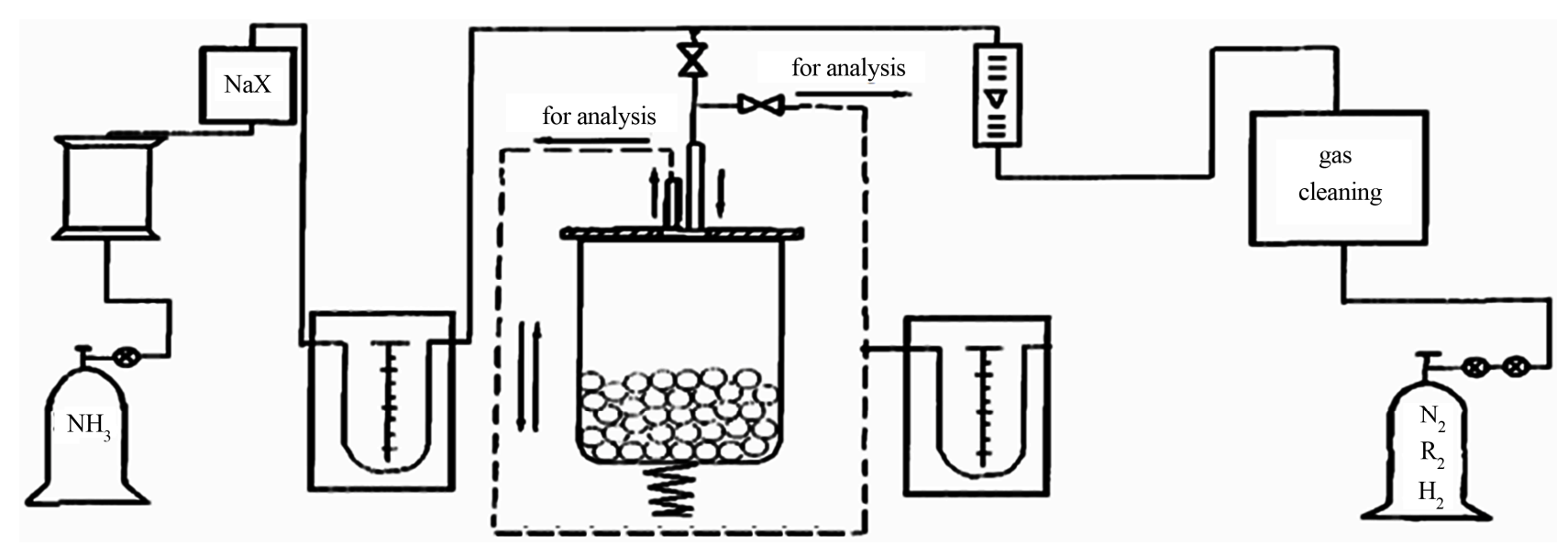

Figure 1. The schematic process of mechanical alloying used in SPbSPU [2]. 


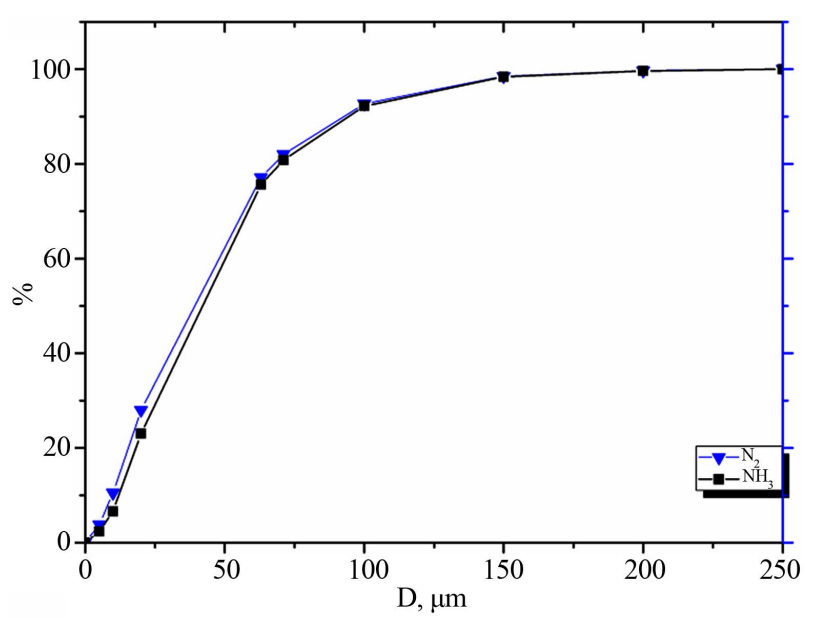

Figure 2. Size distribution of the Fe-18Cr-8Ni-12Mn-N alloy depending on mechanical alloying atmosphere.

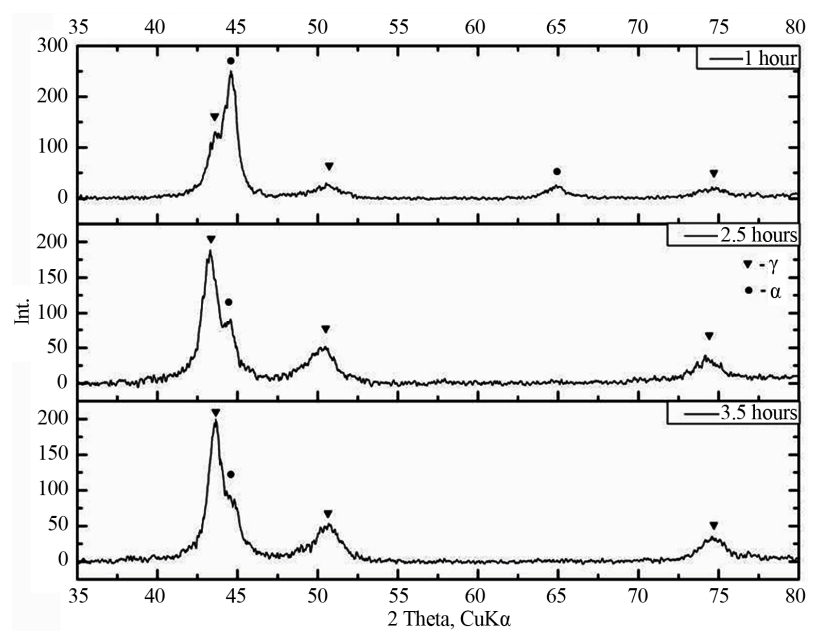

(a)

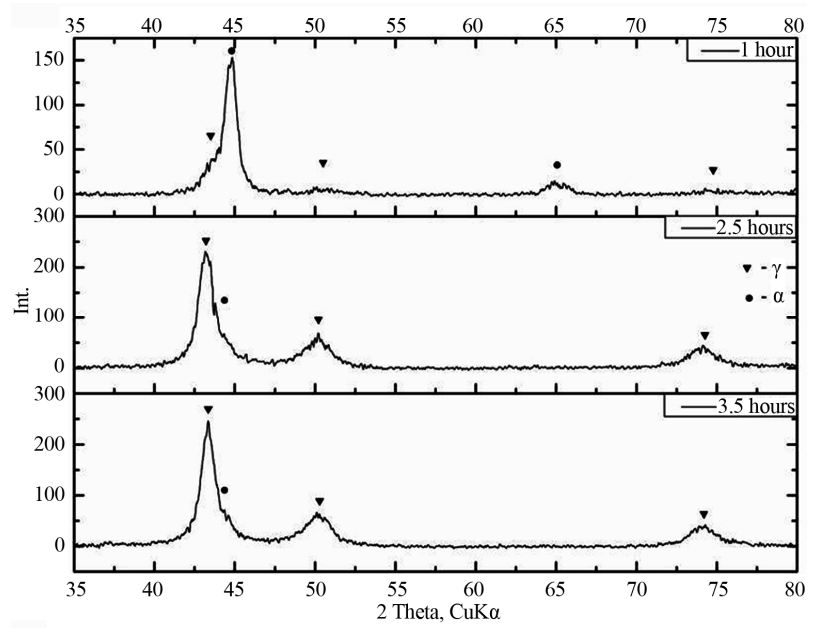

(b)

Figure 3. The phase composition change of the of the Fe$18 \mathrm{Cr}-8 \mathrm{Ni}-12 \mathrm{Mn}-\mathrm{N}$ alloy as a function of mechanical activation and atmosphere time: a) nitrogen; b) ammonia.

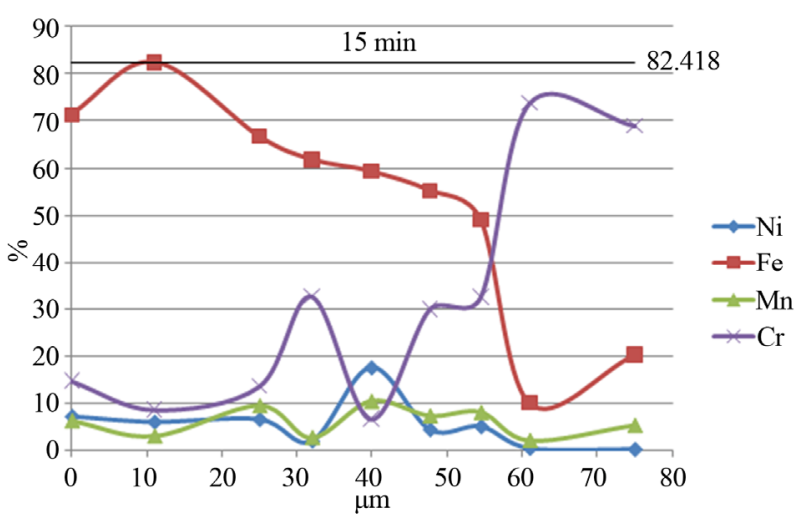

(a)

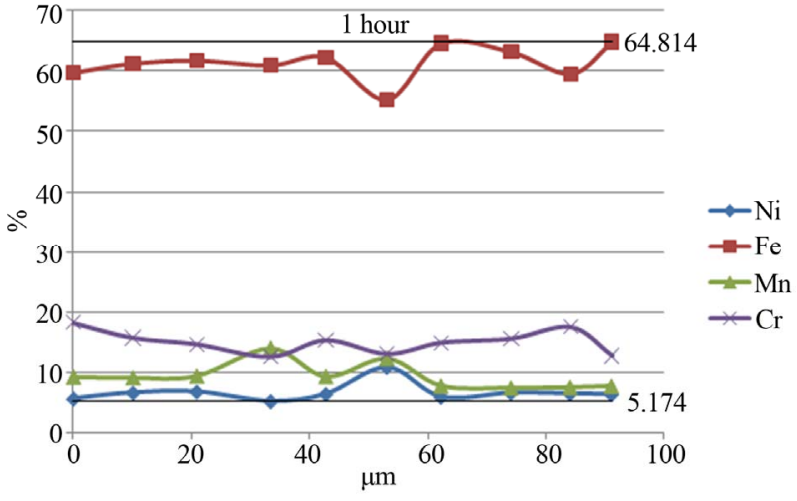

(b)

Figure 4. The distribution of elements in the volume of powder particles for the $\mathrm{Fe}-18 \mathrm{Cr}-8 \mathrm{Ni}-12 \mathrm{Mn}-\mathrm{N}$ alloy depending on the time of mechanical activation: a) $15 \mathrm{~min}$; b) 1 hour.

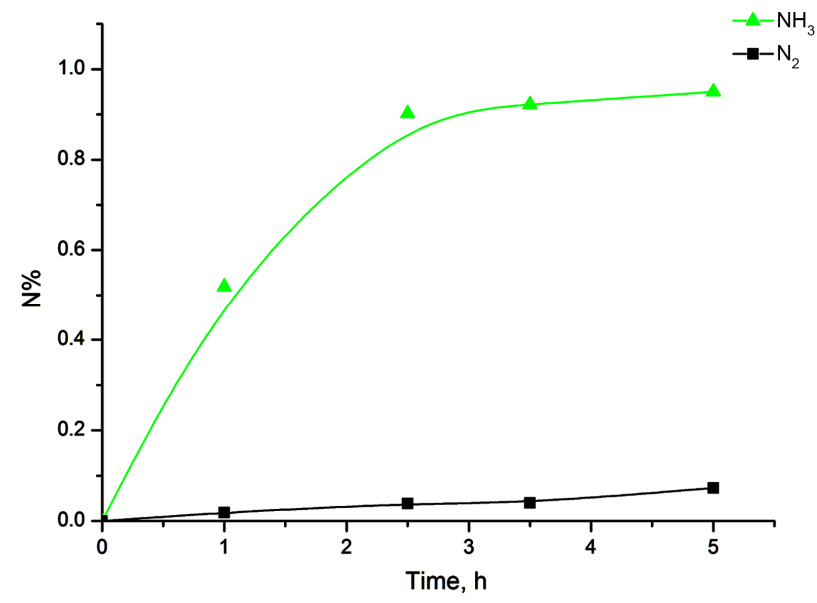

Figure 5. The changing of the nitrogen content in the Fe-18Cr-8Ni-12Mn-N alloy depending on the time of mechanical activation and atmosphere.

have face-centered cubic lattice. In was found that nanocrystals boundaries, studied at higher magnification (Figure 6 (b)), accumulated a lot of dislocations, but the atomic plane partially coherent. Figures 7 (a) and (b)) show the nanocrystalline structure of mechanically al- 


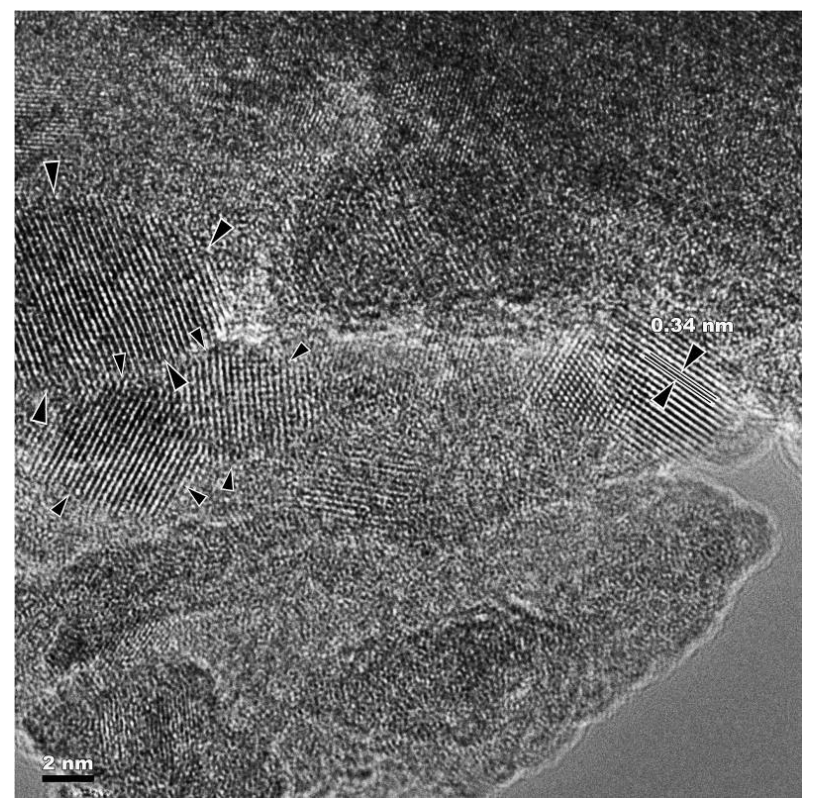

(a)

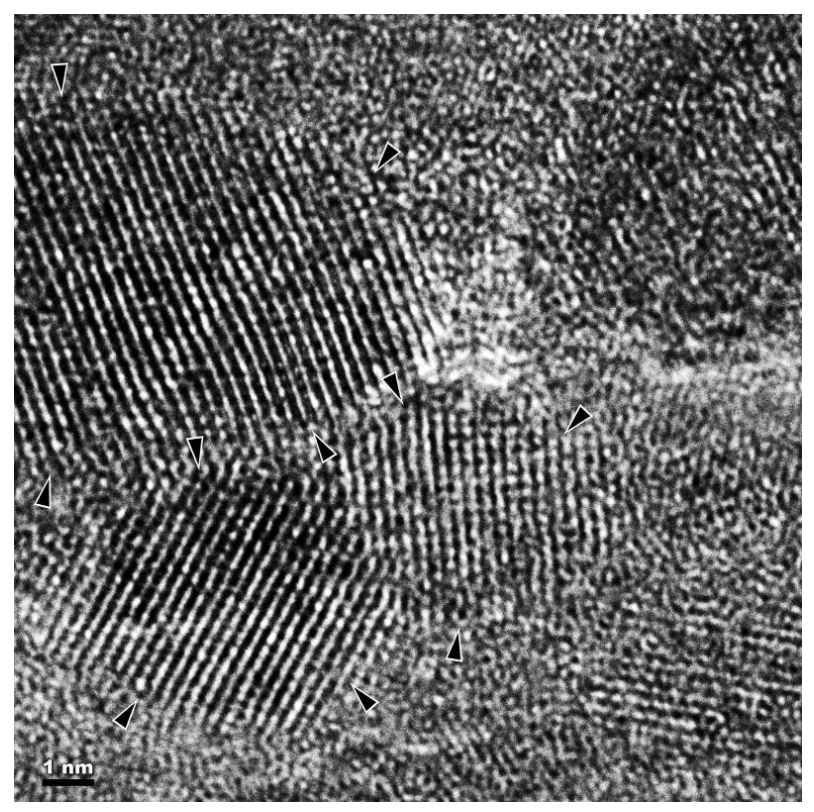

(b)

Figure 6. The typical nanocrystalline structure of mechanically alloyed high-nitrogen powder alloy of $\mathrm{Fe}-18 \mathrm{Cr}-8 \mathrm{Ni}$ 12Mn-0.9N system.

Table 1. The average grain diameter-D, Vickers microhardness-HV.

\begin{tabular}{ccc}
\hline Sample & \multicolumn{1}{c}{$\mathrm{D}, \mathrm{nm}$} & HV \\
\hline Before rolling & $\alpha$-Fe: $18-25 \mathrm{~nm}$ & $540-560$ \\
$\gamma$-Fe: $30-36 \mathrm{~nm}$ & \\
After rolling & $\alpha$-Fe: $32-38 \mathrm{~nm}$ & $410-420$ \\
SUS 321 & 75,000 & $160-180$ \\
\hline
\end{tabular}

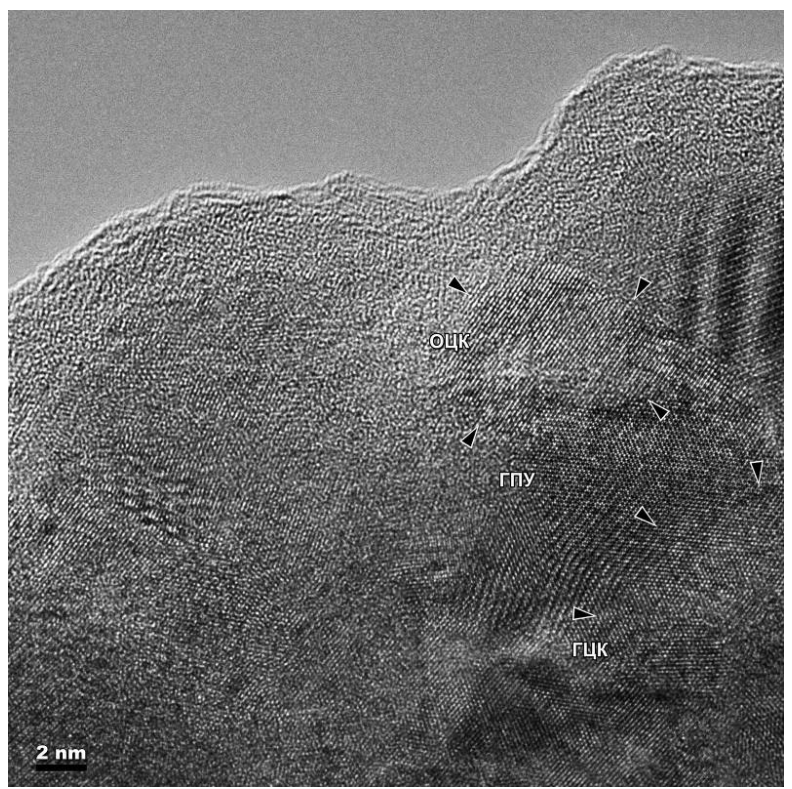

(a)

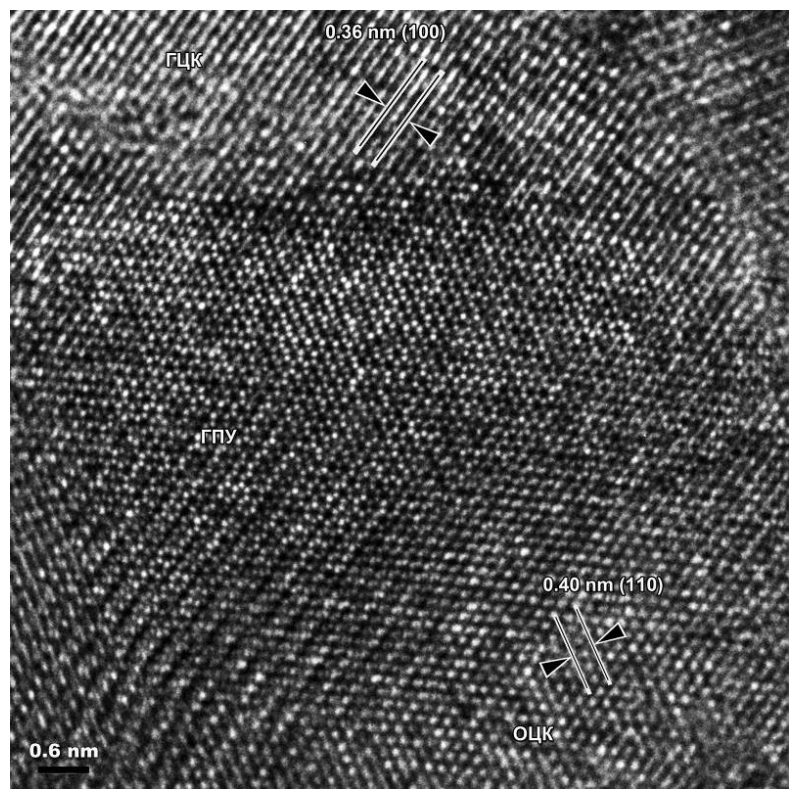

(b)

Figure 7. Nanocrystalline structure of mechanically alloyed powder alloy of Fe-18Cr-8Ni-12Mn-0.04N system.

loyed powder of Fe-18Cr-8Ni-12Mn-0.04N system, obtained by mechanical synthesis in a nitrogen atmosphere with increased cooling rate compared with the alloys presented above. Nanocrystal size of the represented alloy is smaller than $20 \mathrm{~nm}$. The main result of the obtained alloy study is that the formation of the face-centered cubic (fcc) lattice occurs from body-centered cubic (bcc) through an intermediate hexagonal close-packed lattice (Figure 7(b)), which is also confirmed by XRD (Figure 8). On the other alloys this finding was not observed. 


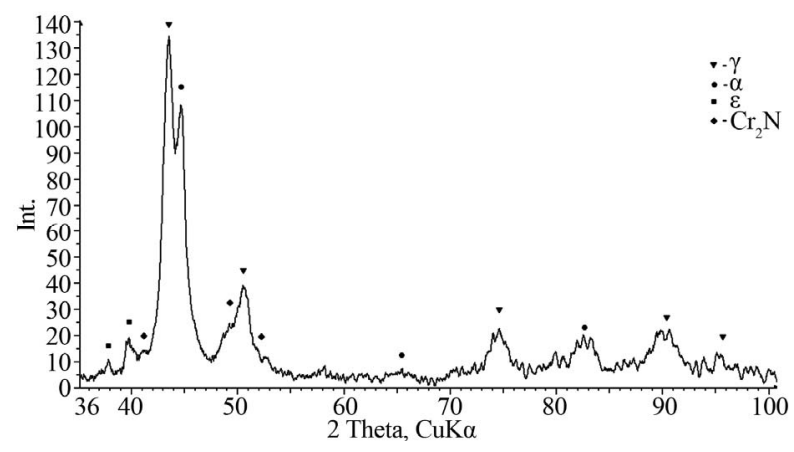

Figure 8. XRD of the Fe-18Cr-8Ni-12Mn-0.04N alloy, obtained by mechanical synthesis in a nitrogen atmosphere with increased cooling rate.

Obtained powders of the Fe- $18 \mathrm{Cr}-8 \mathrm{Ni}-12 \mathrm{Mn}-\mathrm{N}$ alloy have been rolled into a shell at $800^{\circ} \mathrm{C}-900^{\circ} \mathrm{C}$. The rolling scheme is shown in Figure 9. Porosity of the resulting rolled sample is $1 \%$, the nitrogen content in the sample after rolling- $-0.78 \%$.

Table 1 shows an average diameter value of the nanocrystals obtained by BRUKER D8 ADVANCE, and the value of Vickers microhardness of the Fe- $18 \mathrm{Cr}-8 \mathrm{Ni}$ $12 \mathrm{Mn}-0.9 \mathrm{~N}$ alloy before and after rolling. These data indicate that after hot rolling nanocrystalline structure has retained in the alloy, and the obtained compact sample has significantly higher microhardness than the microhardness of similar steel obtained in conventional manner. Subsequent quenching of the samples from $1100^{\circ} \mathrm{C}$ provides a fully austenitic structure of the alloy.

\section{Conclusion}

High-alloy austenitic powders with super equilibrium nitrogen content and the size of the austenite nanocrystals 30 - $36 \mathrm{~nm}$ were obtained as a result of mechanical alloying in an atmosphere of ammonia from powders of iron, chromium, nickel and manganese which were obtained. It is important to note that using mechanical alloying without thermal treatment allows not only to contain a certain composition of the alloy powder with nanocrystalline structure, but also to change the lattice (the original bcc lattice of iron into fcc). Consequently, mechanochemical method can be used to produce high-nitrogen austenitic alloy powders with nanocrystalline structure. It should also be noted that hot rolling technology of the austenitic high-alloy powder alloys with super equilibrium nitrogen provides a sheet with preserved nanocrystalline structure, and that microhardness is much higher than the microhardness of a similar steel produced in the conventional way.

\section{Acknowledgements}

This work is done in accordance with state contract No.

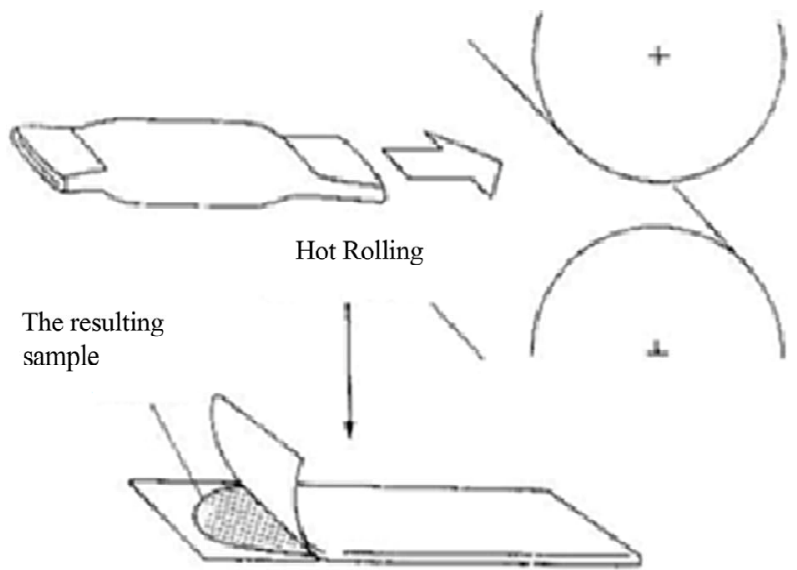

Figure 9. Rolling scheme of Fe-18Cr-8Ni-12Mn-N powder alloy in the shell.

16.740.11.0557 to perform research for public use under the federal target program "Scientific and scientific pedagogical personnel of innovative Russia" for 20092013.

\section{REFERENCES}

[1] I. V. Gorynin, V. A. Malyshevsky, et al., "CorrosionResistant High-Strength Nitrogen Alloying Steel," Problems of Materials Science, Vol. 3, No. 59, 2009, pp. 7-16.

[2] V. V. Boldyrev, "Mechanochemistry and Mechanical Activation of Solids," Russian Chemical Reviews, Vol. 75, No. 3, 2002, pp. 203-206.

[3] C. Suryanarayana, "Mechanical Alloying and Milling," Progress in Materials Science, Vol. 46, 2001, pp. 1-184.

[4] A. A. Popovich, "Mechanochemical Synthesis of Refractory Compounds," FENTU, Vladivostok, 2003.

[5] M. M. Cisneros, "Development of Austenitic Nanostructures in High-Nitrogen Steel Powders Processed by Mechanical Alloying," Metallurgical and Materials Transactions, Vol. 33, No. 7, 2002, pp. 2139-2144. doi:10.1007/s11661-002-0045-1

[6] T. Tsuchiyama, "Fabrication of Fine-Grained High Nitrogen Austenitic Steels through Mechanical Alloying Treatment," ISIJ International, Vol. 42, No. 12, 2002, pp. 1438-1443.

[7] M. M. Cisneros, "Processing of Nanostructured High Nitrogen Stainless Steel by Mechanical Alloying," Metallurgical and Materials Transactions, Vol. 36A, No. 5, 2005, pp. 1299-1316.

[8] A. A. Popovich, T. A. Popovich and O. V. Arestov, "Kinetics and Structure of Refractory Compounds and Alloys Obtained by Mechanical Alloying," Journal of Material Science and Technology, Vol. 7, No. 1, 2001, pp. 63-65. 